\title{
Effect of 8-week core training exercises on physical and physiological parameters of female handball players
}

\author{
Genc H. ${ }^{1 \mathrm{ABCDE}}$, Cigerci A.E. ${ }^{2 \mathrm{ABCDE}}$, Sever O. ${ }^{3 \mathrm{ACDE}}$ \\ ${ }^{1}$ School of Physical Education and Sports, Bingol University, Bingol, Turkey \\ ${ }^{2}$ School of Physical Education and Sports, Kastamonu University, Kastamonu, Turkey \\ ${ }^{3}$ Faculty of Sports Science, Ataturk University, Erzurum, Turkey
}

Authors' Contribution: A - Study design; B - Data collection; C - Statistical analysis; D - Manuscript Preparation; E - Funds Collection

\begin{abstract}
Purpose: $\quad$ Aim of this study was to investigate the effect of 8 weeks core training program on some physiological and physical parameters of handball team's female players.

Material: $\quad$ Volunteers were separated two groups as CTG (training group) and CG (control group). CTG was applied core strength training 30 min sessions 8 weeks and 3 days per week additionally handball trainings. CG wasn't applied any core training. Effects of different core training regimes were compared after eight weeks with repeated measures MANOVA for the tests.

Results: $\quad$ Neither group demonstrated difference for body composition measurements for repeated test scores and between groups comparisons. Significant difference was found BFP (body fat percentage) parameters on CTG. Sprint, agility, SLJ (standing long jump) scores did not increase in any groups and no difference was found between groups. Significance was found in VJ (vertical jump), back and leg strength, right and left hand grip strength, flexibility, balance parameters on CTG. Also significance was found in all core parameters on CTG.

Conclusions: Results indicate that core trainings were very effective on performance based features especially on strength and core stability. So these exercises should be included in the training programs of female handball players.

Keywords: core training, female students, handball, performance analysis.
\end{abstract}

\section{Introduction}

The aim in sport is to develop sporty athletes' physical suitability and maximize sporting success. In order to achieve the desired sporty success, it is necessary to have a high morphological structure in the branch as well as the motoric characteristics that can fulfill the requirements of the branch. Core training can be done by helping to maximize these features. Because the greater the core power, the greater the power generation in the arms and legs [1].

The "core musculature" can be defined generally as the 29 pairs of muscles that support the lumbo-pelvichip complex in order to stabilize the spine, pelvis, and kinetic chain during functional movements [2]. The core muscle is defined as the muscles around the spine and the abdomen, and functions essentially to maintain spinal stability and pelvic balance [3]. Core strengthening has come into prominence in sports training as a method to condition athletes with the hope of preventing injury to the spine and/or extremities. The main emphasis of core strengthening is focused on muscular stabilization of the abdominal, paraspinal, and gluteal muscles to provide better stability and control for sporting activity [4].

Handball is a very strenuous body-contact team sport that places heavy emphasis on running, jumping, running speed, and throwing, and requires substantial strength levels to hit, block, push, and hold during game actions [5]. Core strength is an essential part of any athlete's total fitness. Handball athletes cannot ignore this facet in their physical training because handball is not a one

\footnotetext{
(c) Genc H., Cigerci A.E., Sever O., 2019
}

doi:10.15561/20755279.2019.0604 dimensional game; players are constantly shifting their body from side to side or rotating their bodies toward the ball. One strategic level of handball requires that one keeps their opponents running and off-balance, hence many directional changes during a match.

In order to improve athletic performance, we need to work out what features core training has developed, which is a type of training that teams use frequently, and in which period it should be applied. It's thought that with the strengthening of the core area the needed features when playing handball such as balance, agility, speed and jump will increase.

In this study, it is aimed to measure the effects of core training applied to handball players on these parameters. It is thought that knowing the effect of the core training sessions on the physical and physiological characteristics of the athlete will guide the athletes and the coaches as well as contribute to the sports sciences.

\section{Material and Methods}

Subjects: After the pre-test period, 20 athletes were divided into two groups; 10 core training group (CTG) and 10 control group (CG). For the sake of no difference between the groups in terms of both physical and physiological terms; the final state of the groups was determined in the form of $10 \mathrm{CTG}$ (age $=17.80 \pm 1.4$ years, height $=153.2 \pm 5.8 \mathrm{~cm}$, weight $=60.03 \pm 7.9 \mathrm{~kg})$, $10 \mathrm{CG}$ (age $=17.60 \pm 1.89$ years, height $=166.6 \pm 5.8 \mathrm{~cm}$, weight $=63.30 \pm 6.3 \mathrm{~kg}$ ). In addition, parental signed consent was obtained from parents of each player to participate in the study. 
Procedures: During the application phase of the study, subjects were applied an 8-week core training program, except for their own training days. During the training period, subjects did not participate in any training programs for basic motoric features, they just participated in technical and tactical training programs of their team. CTG participated in the core training program for approximately 60 minutes, including 20 minutes of warm-up and 10 minutes of cool-up exercises in 3 days (Monday, Wednesday, Friday).

Training Plan: The trainings of the CTG were carried out in the sports hall of the club under the supervision of the researchers. The training hour was 18:00 for each training. The training program was planned to be 10 repetitions and 2 sets for each movement for first week and the subjects were given 1 minute between repetitions and 3 minutes between sets in order to provide full recovery. Besides, the number of repetitions was increased each week, additional movements were added in fifth and seventh weeks, adhering to the principle of progressive increase of load [6] as the athletes develop adaptations to the training. In Table 1, there is an 8-week training program applied to CTG.

Physical Measurements: In this section under the title of physical measurements, the information about height, weight, body mass index (BMI) and body fat percentage (BFP) measurements of the subjects participating in the study will be explained.

The height of the subjects participating in the study was measured with Holtain brand stadiometer with a sensitivity of $0.01 \mathrm{~cm}$. The length of the subjects was determined in anatomical position (barefoot) and the result was recorded as "cm". The weight measurements of the subjects were measured with a sensitivity of $0.01 \mathrm{~kg}$ in anatomical position (barefoot) and the result was recorded as "kg". BMI values were determined by "BMI = weight $(\mathrm{kg}) /(\text { height })^{2 "}$ formula. BFP values were obtained by bioimpedance analysis (Tanita MC 780; Tokyo, Japan).

Motoric Performance and Field Measurements: In the study, various tests were used to determine the performance characteristics of handball players.

Dynamometers were used especially when determining strength characteristics. Pro Agility and 505 tests to determine agility skills, 10 and $30 \mathrm{~m}$ test to assess their speed and acceleration abilities were applied to handball players. In addition, the lower extremity explosive force of the athletes was evaluated with standing long jump in horizontal direction and vertical jump tests. Sit and reach test was also applied to subject to determine flexibility and Star Excursion Balance Test (SEBT) was used to measure balance skills. Besides, plank, isometric back extension endurance, sit up and push up tests were applied to determine core stability and endurance features of subjects. Before the measurements, the athletes were warmed up and flexibility exercises were applied.

Muscular strength tests: Handgrip strength was measured for right and left hands with a dynamometer (Takei, Japan). The subjects were placed sitting with $0^{\circ}$ of shoulder flexion, $90^{\circ}$ of elbow flexion, and the forearm in neutral. Maximal back strength and leg strength were measured using a back and leg muscle dynamometer (Takei, Japan). The length of the handle chain was adjusted to fit each subject, so that the angle of the subjects' knees was at $45^{\circ}$. Two trials were performed in each exercise. The best score of two measurements was recorded [7].

Pro agility test: Markers were placed at 0,5 , and 10 yards with timing gates on the 5-yard line, to indicate where participants start and finish. Participants began in a neutral 3-point position with feet either side of the midline, participants then turned and ran 5 yards to the right side and touched the line with the right hand, and then ran 10 yards to the left, touched the line with their left hand the ran back through the start line to the finish. The trial was then completed in the other direction, with a third trial completed off the preferred foot. The fastest trial was recorded [8].

505 agility test: Subjects sprinted forward from the $15-\mathrm{m}$ cones and the timing began once they passed the $5-\mathrm{m}$ cones. When the subjects reached the $0-\mathrm{m}$ cones, the subject made a $180^{\circ}$ change of direction and sprinted

Table 1. 8-week core training program

\begin{tabular}{|c|c|c|c|c|c|c|c|c|}
\hline Movements & $\begin{array}{l}1^{\text {st }} \\
\text { Week }\end{array}$ & $\begin{array}{l}2^{\text {nd }} \\
\text { Week }\end{array}$ & $\begin{array}{l}3^{\text {rd }} \\
\text { Week }\end{array}$ & $\begin{array}{l}4^{\text {th }} \\
\text { Week }\end{array}$ & $\begin{array}{l}5^{\text {th }} \\
\text { Week }\end{array}$ & $\begin{array}{l}6^{\text {th }} \\
\text { Week }\end{array}$ & $\begin{array}{l}7^{\text {th }} \\
\text { Week }\end{array}$ & $\begin{array}{l}8^{\text {th }} \\
\text { Week }\end{array}$ \\
\hline Uneven Plank & $2 \times 10$ & $2 \times 15$ & $2 \times 20$ & $2 \times 25$ & $2 \times 25$ & $2 \times 30$ & $2 \times 30$ & $2 \times 35$ \\
\hline Crunch & $2 \times 10$ & $2 \times 15$ & $2 \times 20$ & $2 \times 25$ & $2 \times 25$ & $2 \times 30$ & $2 \times 30$ & $2 \times 35$ \\
\hline Abdominal Oblique Side Plank & $2 \times 10$ & $2 \times 15$ & $2 \times 20$ & $2 \times 25$ & $2 \times 25$ & $2 \times 30$ & $2 \times 30$ & $2 \times 35$ \\
\hline Super Plank with Leg Raise & $2 \times 10$ & $2 \times 15$ & $2 \times 20$ & $2 \times 25$ & $2 \times 25$ & $2 \times 30$ & $2 \times 30$ & $2 \times 35$ \\
\hline Lying Side Crunch & $2 \times 10$ & $2 \times 15$ & $2 \times 20$ & $2 \times 25$ & $2 \times 25$ & $2 \times 30$ & $2 \times 30$ & $2 \times 35$ \\
\hline Superman & $2 \times 10$ & $2 \times 15$ & $2 \times 20$ & $2 \times 25$ & $2 \times 25$ & $2 \times 30$ & $2 \times 30$ & $2 \times 35$ \\
\hline V-Up & & & & & $2 \times 25$ & $2 \times 30$ & $2 \times 30$ & $2 \times 35$ \\
\hline Windshield Wipers & & & & & $2 \times 25$ & $2 \times 30$ & $2 \times 30$ & $2 \times 35$ \\
\hline One Arm / Leg Plank Balance & & & & & $2 \times 25$ & $2 \times 30$ & $2 \times 30$ & $2 \times 35$ \\
\hline Mountain Climber & & & & & & & $2 \times 30$ & $2 \times 35$ \\
\hline Single Leg Bridge & & & & & & & $2 \times 30$ & $2 \times 35$ \\
\hline Air Bike Crunches & & & & & & & $2 \times 30$ & $2 \times 35$ \\
\hline
\end{tabular}


back through the 5-m cones, at which point the timer was stopped. All subjects completed 3 trials of the 505 agility test with 2-5 minutes' rest between each trial [9].

\section{Vertical jump test}

The vertical jump (VJ) is one of the most frequently used tests of power and explosiveness in strength and conditioning [10]. Standing erect with the feet flat on the floor, the client reaches as high as possible on the tape, with the arm and fingers fully extended and the palm toward the wall. This is recorded as the beginning height. Standing about a foot away from the wall, the individual brings the arms downward and backward, while bending the knees to a balanced semisquat position, and then jumps as high as possible, with the arms moving forward and upward. The tape should be touched at the peak height of the jump with the fingers of the arm facing the wall [11]. The best of three trials were recorded as "cm".

\section{Standing long jump test}

The standing long jump (SLJ) is another frequently used test of lower body explosive performance. This test may be used in conjunction with the VJ test, because it provides information about vertical and horizontal displacement. The measurement was made between the heel where the subject touched down after the horizontal jumping from the starting line and the best of three trials were recorded as "cm" $[10,12]$.

$10 \mathrm{~m}-30 \mathrm{~m}$ speed and acceleration tests: The speed skills of the subjects were measured by 10 and 30 meter tests. The subjects started the test from the starting line located 1 meter behind the starting photocell (Newtest 2000; Newtest Oy, Oulu, Finland). Acceleration and speed values of the subjects were recorded through the photocells placed at $10^{\text {th }}$ and $30^{\text {th }}$ meter. Each participant repeated the test twice, and the best one was recorded as "seconds".

Flexibility test: Flexibility of the trunk was determined from a sit-and-reach test using a standard sit-and-reach box. The subjects sat in front of a sit-and-reach testing box, where the feet meet the testing box. The subjects were informed to reach forward, with palms down and one hand on top of the other along the measuring scale of the testing box. The recorded score for this test was the average of 2 trials [7].

Star Excursion Balance Test (SEBT): The SEBT was performed with the participants standing in the middle of a grid formed by eight lines extending out at $45^{\circ}$ from each other. The participant was asked to reach as far as possible along each of the eight lines, make a light touch on the line, and return the reaching leg back to the center, while maintaining a single-leg stance with the other leg in the center of the grid. Participants were instructed to make a light touch on the ground with the most distal part of the reaching leg and return to a double-leg stance without allowing the contact to affect overall balance. They began with the anterior direction and progressed clockwise around the grid. All participants began with a right stance leg in the center of the grid. After completion of the three trials in the eight directions and 5-min rest period, the test continued with a left stance leg. The balance score was calculated by using the formula, "reach distance/leg length x 100" [13].

Core stability and endurance tests: Plank, isometric back extension endurance, sit up and push up tests were applied to determine core stability and endurance features of handball players.

Plank test

The plank protocol required participants to maintain a static prone position with only forearms and toes touching the ground. Proper form required feet together with toes curled under the feet, elbows forearm distance apart, and hands clasped together against the floor mat. Participants maintained eye contact with their hands, a neutral spine, and a straight line from head to ankles. The child was given one 5-s practice trial, and the examiner instructed the child into the proper position, followed by a brief period of rest. The test began when the participant demonstrated the correct position. Participants were allowed to deviate from the correct position once and could continue the test if they immediately resumed the correct starting position. The test was terminated on the second deviation from the correct position or if the participant did not return to the correct position after the first warning [14].

Isometric back extension endurance test

Endurance was evaluated by timing (holding time measured in seconds) how long the subject was able to hold the upper part of the body horizontal, while lying prone, with no support beyond the upper border of the iliac crest. The hands were kept behind the neck and the thighs and ankles were fixed to the table by 2 wide straps. Subjects were instructed to hold the position as long as they could. During testing, subjects received encouragement once if their position fell under the horizontal level. The position was indicated by a plumb bob hanging from the ceiling that was adjusted to contact the back when the horizontal position was maintained. If the position was not immediately corrected, or if the subject claimed that the position could no longer be held due to fatigue or discomfort, the test ended and the holding time was recorded [15].

Sit up and push up tests

These tests were applied to subjects for 1 minute and only proper applications of subjects in this time were recorded as sit up and push up scores.

Statistical Analysis.

The data obtained from the pre and post-training measurements of handball players were analyzed in the IBM SPSS 19 statistical program. Descriptive statistics are categorized according to all handball players and groups. The pre and post-test distributions of the variables were examined according to groups, the normality of the distributions and the homogeneity of the variance were determined by the Mauchly's Sphericity Test and the Levene Test. Analysis of intergroup, intra group and the effect of training was carried out with multiple analysis of variance (MANOVA) in repeated measurements. Bonferroni test was used for Post Hoc comparisons, the significance level was accepted as 0.05 . 


\section{Results}

The average age, height, weight and BMI of 20 handball players were seen as $17.7 \pm 1.6,166.1 \pm 5.6$, $61.6 \pm 10.80,22.14 \pm 2.4$, respectively.

There is no significant difference between groups before the training period for all descriptive variables (tabl. 2).

The pre and post-test measurements of physical characteristics of the subjects, such as weight, BMI and $\mathrm{BFP}$, are compared in terms of inter-group, intra-group and group*test interaction (tabl. 3). According to this, the increase in the weight and the decrease in BMI values of CTG was statistically significant, whereas these data were not statistically significant. In the BFP values, group*test interaction was seen and it was understood that this interaction resulted from CTG.

As can be seen from the results that significance was found in VJ, back and leg strength, right and left hand grip strength, flexibility, balance parameters in favor of CTG. Also significance was found in all core parameters on CTG. These significances affect the test* group interaction $(\mathrm{p}<0.05)$.

Table 2. Descriptive statistics of handball players and comparison of physical measurements among groups

\begin{tabular}{|c|c|c|c|c|c|c|c|}
\hline Group & & & $\begin{array}{l}\text { Mean-Standard } \\
\text { Deviation }\end{array}$ & Min. & Max. & \multicolumn{2}{|c|}{$\begin{array}{l}\text { Comparison Between } \\
\text { Groups }\end{array}$} \\
\hline & CTG & Age & $17.80 \pm 1.4$ & 16 & 18 & & \\
\hline & \multirow[t]{2}{*}{$(n=10)$} & Height (cm) & $153.2 \pm 5.8$ & 145.6 & 171.8 & & \\
\hline & & Weight (kg) & $60.03 \pm 7.9$ & 43.1 & 69.6 & & \\
\hline & CG & Age & $17.60 \pm 1.89$ & 16 & 18 & & \\
\hline & \multirow[t]{2}{*}{$(n=10)$} & Height $(\mathrm{cm})$ & $166.6 \pm 5.8$ & 153.4 & 171.5 & & \\
\hline & & Weight (kg) & $63.30 \pm 6.3$ & 51.1 & 70.4 & Chi-Square & $\mathrm{P}$ \\
\hline & TOTAL & Age & $17.7 \pm 1.6$ & 16 & 18 & -0.397 & 0.691 \\
\hline & \multirow[t]{2}{*}{$(n=20)$} & Height $(\mathrm{cm})$ & $166.1 \pm 5.6$ & 145.6 & 171.7 & -0.454 & 0.650 \\
\hline & & Weight (kg) & $61.6 \pm 10.80$ & 43.1 & 70.4 & -0.984 & 0.325 \\
\hline
\end{tabular}

$*_{p}<0.05$

Table 3. Comparison of pre and post-test changes of physical features of groups

\begin{tabular}{|c|c|c|c|c|c|c|c|}
\hline & Group & $\mathbf{N}$ & Pre-Test & Post-Test & $\begin{array}{l}\text { Intra-Group } \\
\text { Change (\%) }\end{array}$ & $\begin{array}{l}\text { Test*Group } \\
\text { F }\end{array}$ & $\mathbf{p}$ \\
\hline \multicolumn{8}{|c|}{ Physical Features } \\
\hline & CTG & 10 & $60.03 \pm 7.9$ & $60.19 \pm 7.8$ & $0.16(0.27)^{*}$ & & \\
\hline \multirow[t]{3}{*}{ Weight (kg) } & & & & & & 0.075 & 0.788 \\
\hline & CG & 10 & $63.30 \pm 6.3$ & $63.43 \pm 6.2$ & $0.13(0.21)$ & & \\
\hline & CTG & 10 & $22.07 \pm 1.91$ & $21.98 \pm 1.84$ & $-0.09(-0.41)^{*}$ & & \\
\hline \multirow[t]{3}{*}{ BMI } & & & & & & 0.615 & 0.443 \\
\hline & CG & 10 & $22.21 \pm 2.07$ & $22.16 \pm 2.02$ & $-0.05(-0.96)$ & & \\
\hline & CTG & 10 & $13.57 \pm 2.32$ & $13.44 \pm 2.32$ & $-0.13(-0.96)^{*}$ & & \\
\hline \multirow[t]{2}{*}{ BFP } & & & & & & 0.575 & $0.017^{*}$ \\
\hline & CG & 10 & $13.63 \pm 2.49$ & $13.59 \pm 2.46$ & $-0.04(-0.29)$ & & \\
\hline
\end{tabular}

${ }^{*} p<0.05$, BMI: Body Mass Index, BFP: Body Fat Percentage 


\section{Discussion}

When the body composition changes of handball players are examined, it was observed that BMI and BFP of CTG decreased by $0.41 \%$ and $0.96 \%$ respectively after the training program and this decrease created statistical significance in the test*group comparison (Table 3). The existing studies which show the effect of core stabilization exercises on body compositions give quite different results from each other and it is considered that this difference is due to the study groups. While studies on sedentary individuals show that in general positive effects have been achieved on body composition [16-19], this effect has not been shown in some other studies [20,21], however a change is mostly not seen in studies with athletes [22]. For example, a Pilates training program that consisted of 7 exercises of 2 to 3 sets with 15 to 20 repetitions each with a 45 -sec rest interval twice a week for 6 weeks (in addition to basketball team training), was not sufficient to change body composition in young basketball athletes [23]. In this study, the application of the training program at the beginning of the season and the differences in body composition in the intra-season, half season stages of athletes [24,25] can explain the change in body composition with training.

Explosive power, agility and speed tests showed that there was a difference between groups for VJ test only and that the core training group increased the jump height by $0.8 \%$ (Table 4 ). Both correlation and experimental studies investigating the effect of core training programs on agility and speed tests reveal different results. Many studies show that the positive effect of core stabilization studies on athletic skills such as jump, speed, agility in which the ability to produce quick power is important remains low [26-30]. In the systematic review carried out by Reed et al., 13 of the 24 studies were conducted with athletes and the majority of the positive performance improvements resulting from these studies were due to sports-related training and sport-specific measurements. It was revealed that the change in performance skills such as basic strength, sprinting and jumping was not sufficiently provable by core stabilization studies [30]. In another study, both dynamic and static working groups, who practice core training on unstable surface, did not develop vertical jump, health ball throwing, $20 \mathrm{~m}$ sprint scores. Increased core stabilization ability as a result of both types of training did not affect sports-related performance [29].

Table 4. Comparison of pre and post-test changes of explosive force, agility and speed and acceleration tests of groups

\begin{tabular}{|c|c|c|c|c|c|c|c|}
\hline & Group & $\mathbf{N}$ & Pre-Test & Post-Test & $\begin{array}{l}\text { Intra-Group } \\
\text { Change (\%) }\end{array}$ & $\begin{array}{l}\text { Test * Group } \\
\mathbf{F}\end{array}$ & $\mathbf{p}$ \\
\hline \multicolumn{8}{|c|}{ Explosive Force Tests } \\
\hline \multirow{4}{*}{ VJ $(\mathrm{cm})$} & CTG & 10 & $32.54 \pm 4.02$ & $32.80 \pm 4.02$ & $0.26(0.80)^{*}$ & & \\
\hline & & & & & & $24.816^{*}$ & 0.001 \\
\hline & CG & 10 & $31.56 \pm 2.49$ & $31.59 \pm 2.46$ & $0.03(0.10)$ & & \\
\hline & CTG & 10 & $163.80 \pm 20.48$ & $164.75 \pm 20.64$ & $0.95(0.58)^{*}$ & & \\
\hline \multirow[t]{2}{*}{$\mathrm{SLJ}(\mathrm{cm})$} & & & & & & 1.692 & 0.210 \\
\hline & CG & 10 & $154.50 \pm 13.96$ & $155.20 \pm 14.11$ & $0.70(0.45)^{*}$ & & \\
\hline \multicolumn{8}{|l|}{ Agility Tests } \\
\hline \multirow{4}{*}{$\begin{array}{l}\text { Pro Agility } \\
\text { (sec) }\end{array}$} & CTG & 10 & $8.17 \pm 0.51$ & $8.14 \pm 0.50$ & $-0.03(-0.37)$ & & \\
\hline & & & & & & 3.060 & 0.096 \\
\hline & CG & 10 & $8.15 \pm 0.40$ & $8.15 \pm 0.20$ & $-0.001(-0.01)$ & & \\
\hline & CTG & 10 & $4.86 \pm 0.19$ & $4.83 \pm 0.19$ & $-0.03(-0.62)^{*}$ & & \\
\hline \multirow{2}{*}{$\begin{array}{l}505 \text { Agility } \\
\text { (sec) }\end{array}$} & & & & & & 0.450 & 0.511 \\
\hline & CG & 10 & $4.86 \pm 0.20$ & $4.83 \pm 0.20$ & $-0.03(-0.62)^{*}$ & & \\
\hline \multicolumn{8}{|c|}{ Speed and Acceleration Tests } \\
\hline \multirow{4}{*}{$10 \mathrm{~m}(\mathrm{sec})$} & CTG & 10 & $2.10 \pm 0.20$ & $2.09 \pm 0.20$ & $-0.01(-0.48)$ & & \\
\hline & & & & & & 0.096 & 0.760 \\
\hline & CG & 10 & $2.14 \pm 0.13$ & $2.13 \pm 0.12$ & $-0.01(-0.47)^{*}$ & & \\
\hline & CTG & 10 & $5.13 \pm 0.52$ & $5.12 \pm 0.51$ & $-0.01(-0.19)^{*}$ & & \\
\hline \multirow[t]{2}{*}{$30 \mathrm{~m}(\mathrm{sec}$} & & & & & & 0.356 & 0.558 \\
\hline & CG & 10 & $5.25 \pm 0.37$ & $5.24 \pm 0.36$ & $-0.01(-0.19)^{*}$ & & \\
\hline
\end{tabular}

${ }^{*} p<0.05$, VJ: Vertical Jump, SLJ: Standing Long Jump 
Some studies also show positive development in lower extremity power output with core stabilization training [31-33]. For example, as a result of core strength training applied to 19 young players on stable and unstable surfaces with football training, while trunk extension strength increased by $5 \%$, this increase improved $10-20 \mathrm{~m}$ sprint performance by $3 \%$ and shot speed by $1 \% 33$. However, it was revealed some developments in core rotational power related to the upper extremity, such as hitting, throwing in many studies [34-36]. It can be generally said that the contribution of core stabilization studies to various power tests differ, but the effect of lower extremity power and power tests is less than the effect of upper extremity tests. As in this study, core exercises only include body stabilization exercises to strengthen global and local muscles, hip joint muscles that provide the link to the lower extremity cannot activate enough in these exercises may explain this situation.

It was observed that the training program had a significant impact on both the sit and reach test and the balance test (Table 5). After the training program, the sit and reach score increased by $13.54 \%$ in CTG, and the right and left SEBT scores increased by $5.74 \%$ and $2,2 \%$, respectively. In all tests, the test*group relationship was statistically significant. In this respect, the core training program has significantly increased the flexibility of the spine (especially thoracic and lumbar), hamstring flexibility and balance skill. There are many studies in the literature that show that balance test scores have increased thanks to the development of core stabilization skills [19, 29, 37-40]. In a 12-week body stabilization study conducted with 17 male footballer, the static and dynamic balance skills of athletes increased significantly compared to the control group [41]. In addition, the opposite of this, it was said that balance exercises also increased the test performance of core stability [42]. The relationship between flexibility and core stabilization training is not seen as much. However, the development of flexibility in this study can be explained by assuming that studies involving the applications of pilates [20, 43] in which similar core exercise structures are being studied. For example, as a result of pilates exercises applied by 20 people for 45 minutes and two days per week for 8 weeks, measurements were made using sit and reach and lumbo-pelvic stabilization tests. In 0,4 and 8 week scores of subjects were $27.69 \mathrm{~cm}, 31.77 \mathrm{~cm}$ and 34.89 $\mathrm{cm}$, respectively. In the study, in addition to lumbo-pelvic stabilization, the flexibility characteristics of the subjects were improved [43].

For all muscular strength and endurance measurements, the CTG shows significant improvement compared to CG (Table 6). According to this, the right-left hand grip strength for CTG was 3.14\%, 3.24\%, and the leg and back strength were $14.1 \%, 13.7 \%$, respectively. The increase in core stability and endurance tests was more pronounced for CTG and the rates of change were seen as $\% 26.27, \% 25.09, \% 19.8, \% 17.44$ in plank, back extension endurance, sit up, push up, respectively. Similar developments were introduced in studies examining core stabilization training and the development of core stabilization and endurance skills [22,28,29]. While the core test-specific performance increased with the Swiss ball stabilization exercises applied twice a week for 6 weeks (Swiss ball prone stabilization core stability test and Sahrmann test of core stability), no change was observed in the running economy at different speeds, myoelectric fatigue level in different muscles, and the running posture [7]. In a study consisting of 10 experimental and 10 control group, $50 \mathrm{~m}$ swimming time developed by $2 \%$ with 12 week core trainings. In addition, medium and high-level

Table 5. Comparison of pre and post-test changes of flexibility and balance tests of groups

\begin{tabular}{|c|c|c|c|c|c|c|c|}
\hline & Group & $\mathbf{N}$ & Pre-Test & Post-Test & $\begin{array}{l}\text { Intra-Group } \\
\text { Change (\%) }\end{array}$ & $\begin{array}{l}\text { Test * Group } \\
\mathbf{F}\end{array}$ & $\mathbf{p}$ \\
\hline \multicolumn{8}{|c|}{ Stand and Reach Test } \\
\hline \multirow{3}{*}{$\begin{array}{l}\text { Flexibility } \\
(\mathrm{cm})\end{array}$} & CTG & 10 & $24.00 \pm 6.41$ & $27.25 \pm 7.22$ & $3.25(13.54)^{*}$ & & \\
\hline & & & & & & $6.746 *$ & 0.018 \\
\hline & CG & 10 & $24.65 \pm 8.26$ & $25.15 \pm 8.26$ & $0.50(2.03)^{*}$ & & \\
\hline \multicolumn{8}{|c|}{ Star Excursion Balance Test (SEBT) } \\
\hline \multirow{3}{*}{ SEBT (right) } & CTG & 10 & $637.74 \pm 72.39$ & $674.32 \pm 73.84$ & $36.58(5.74)^{*}$ & & \\
\hline & & & & & & $519.154 *$ & 0.000 \\
\hline & CG & 10 & $643.07 \pm 63.55$ & $648.40 \pm 62.87$ & $5.33(0.83)^{*}$ & & \\
\hline \multirow{3}{*}{ SEBT (left) } & CTG & 10 & $655.96 \pm 102.74$ & $670.41 \pm 100.07$ & $14.45(2.20)^{*}$ & & \\
\hline & & & & & & $38.948 *$ & 0.000 \\
\hline & CG & 10 & $658.84 \pm 81.07$ & $663.20 \pm 80.79$ & $4.36(0.66)^{*}$ & & \\
\hline
\end{tabular}


Table 6. Comparison of pre and post-test changes of muscular strength and core stability and endurance tests of groups

\begin{tabular}{|c|c|c|c|c|c|c|c|}
\hline & Group & $\mathbf{N}$ & Pre-Test & Post-Test & $\begin{array}{l}\text { Intra-Group } \\
\text { Change (\%) }\end{array}$ & $\begin{array}{l}\text { Test * Group } \\
\text { F }\end{array}$ & $\mathbf{p}$ \\
\hline \multicolumn{8}{|c|}{ Muscular Strength Test } \\
\hline \multirow{3}{*}{$\begin{array}{l}\text { Hand Grip } \\
\text { Right (kg) }\end{array}$} & CTG & 10 & $31.17 \pm 4.79$ & $32.15 \pm 4.70$ & $0.98(3.14)^{*}$ & \multirow{3}{*}{$24.816 *$} & \multirow{3}{*}{0.000} \\
\hline & & & & & & & \\
\hline & CG & 10 & $28.30 \pm 4.68$ & $28.54 \pm 4.67$ & $0.24(0.85)^{*}$ & & \\
\hline \multirow{3}{*}{$\begin{array}{l}\text { Hand Grip } \\
\text { Left }(\mathrm{kg})\end{array}$} & CTG & 10 & $27.74 \pm 3.71$ & $28.64 \pm 3.71$ & $0.90(3.24)^{*}$ & \multirow{3}{*}{$81.520 *$} & \multirow{3}{*}{0.000} \\
\hline & & & & & & & \\
\hline & CG & 10 & $27.93 \pm 3.76$ & $28.04 \pm 3.76$ & $0.11(0.39)^{*}$ & & \\
\hline \multirow{3}{*}{$\begin{array}{l}\text { Leg Strength } \\
\text { (kg) }\end{array}$} & CTG & 10 & $104.25 \pm 16.41$ & $118.95 \pm 15.90$ & $14.70(14.10)^{*}$ & \multirow{3}{*}{$439.2^{*}$} & \multirow{3}{*}{0.000} \\
\hline & & & & & & & \\
\hline & CG & 10 & $95.70 \pm 18.36$ & $98.30 \pm 16.61$ & $2.60(2.72)^{*}$ & & \\
\hline \multirow{3}{*}{$\begin{array}{l}\text { Back Strength } \\
(\mathrm{kg})\end{array}$} & CTG & 10 & $92.65 \pm 12.52$ & $106.35 \pm 12.40$ & $13.70(14.79)^{*}$ & \multirow{3}{*}{$108.81 *$} & \multirow{3}{*}{0.000} \\
\hline & & & & & & & \\
\hline & CG & 10 & $88.75 \pm 10.23$ & $93.70 \pm 10.07$ & $4.95(5.58)^{*}$ & & \\
\hline \multicolumn{8}{|c|}{ Core Stability and Endurance Tests } \\
\hline \multirow{3}{*}{ Plank } & CTG & 10 & $93.01 \pm 22.58$ & $117.44 \pm 21.44$ & $24.43(26.27) *$ & \multirow{3}{*}{$282.79 *$} & \multirow{3}{*}{0.000} \\
\hline & & & & & & & \\
\hline & CG & 10 & $87.00 \pm 14.85$ & $89.10 \pm 15.53$ & $2.10(2.41) *$ & & \\
\hline \multirow{4}{*}{$\begin{array}{l}\text { Back } \\
\text { Extension } \\
\text { Endurance }\end{array}$} & CTG & 10 & $110.85 \pm 25.24$ & $138.66 \pm 25.33$ & $27.81(25.09) *$ & \multirow{3}{*}{$171.313^{*}$} & \multirow{3}{*}{0.000} \\
\hline & & & & & & & \\
\hline & CG & 10 & $107.08 \pm 18.56$ & $110.18 \pm 18.05$ & $3.10(2.90) *$ & & \\
\hline & CTG & 10 & $20.20 \pm 1.89$ & $24.20 \pm 1.62$ & $4.00(19.80) *$ & \multirow{3}{*}{$66.818^{*}$} & \multirow{3}{*}{0.000} \\
\hline \multirow[t]{2}{*}{ Sit up (reps) } & & & & & & & \\
\hline & CG & 10 & $19.90 \pm 2.47$ & $20.40 \pm 2.68$ & $0.50(2.51)$ & & \\
\hline \multirow{3}{*}{$\begin{array}{l}\text { Push up } \\
\text { (reps) }\end{array}$} & CTG & 10 & $19.50 \pm 2.72$ & $22.90 \pm 2.56$ & $3.40(17.44) *$ & \multirow{3}{*}{$47.676 *$} & \multirow{3}{*}{0.000} \\
\hline & & & & & & & \\
\hline & CG & 10 & $18.60 \pm 2.50$ & $19.20 \pm 2.90$ & $0.60(3.23)$ & & \\
\hline
\end{tabular}

${ }^{*} p<0.05$

developments were observed in asymmetric straight armpull-down test compared to control group. At the same time, EMG activity of maximal voluntary contraction of core muscles was increased [44].

\section{Conclusion}

As the results show that both training types let the players improve movement related measurements of core stability but did not transfer into any anaerobic skills and body composition. Core stability training is not generate sufficient stimulus to improve power and strength dependent performance skills like sprint and agility and not required to be the main part of handball conditioning programs.

\section{Conflict of interest}

The authors report no conflict of interest. 
1. Willardson JM. Core stability training: Applications to sports conditioning programs. $J$ Strength Cond Res, 2007;21(3):979-985. https://doi.org/10.1519/R-20255.1

2. Fredericson M, Moore, T. Core stabilization training for middle-and long-distance runners. New Studies in Athletics, 2005;20(1):25-37.

3. Akuthota V, Ferreiro A, Moore T, Fredericson M. Core stability exercise principles. Curr Sports Med Rep, 2008;7(1):39-44. https://doi.org/10.1097/01.CSMR.0000308663.13278.69

4. Nadler SF, Malanga, GA, Bartoli LA, Feinberg JH. Prybicien M, DePrince, M. Hip muscle imbalance and low back pain in athletes: influence of core strengthening. Med Sci Sports Exerc, 2002;34(1):9-16. https://doi.org/10.1097/00005768-200201000-00003

5. Wallace MB, Cardinale M. Conditioning for team handball. Strength Condit J, 1997;19(6):7-12. https://doi.org/10.1519/1073-6840(1997)019<0007:CFTH> 2.3.CO;2

6. Bompa TO. Periodization: Training theory and method. Ankara: Spor Yayınevi ve Kitabevi; 2011.

7. Demirkan E, Koz M, Kutlu M, Favre M. Comparison of physical and physiological profiles in elite and amateur young wrestlers. J Strength Cond Res, 2015;29(7):1876-1883. https://doi.org/10.1519/JSC.0000000000000833

8. Speirs DE, Bennett MA, Finn CV, Turner AP. Unilateral vs. bilateral squat training for strength, sprints, and agility in academy rugby players. $J$ Strength Cond Res, 2016;30(2):386-392. https://doi.org/10.1519/JSC.0000000000001096

9. VanGelderLH,BartzSD.Theeffectofacutestretchingonagility performance. J Strength Cond Res, 2011;25(11):3014-3021. https://doi.org/10.1519/JSC.0b013e318212e42b

10.Miller T. NSCA's guide to tests and assessments. Champaign, IL: Human Kinetics; 2012

11.Nieman D. Exercise testing and prescription: A health related approach. 7th ed. New York: McGraw Hill; 2011.

12.Kamar A. Sporda yetenek beceri ve performans testleri [Ability, skill and performance tests in sport]. Ankara: Nobel Yayın Dağıtım; 2003.

13.Gribble PA, Hertel J. Considerations for normalizing measures of the Star Excursion Balance Test. Meas Phys Educ Exerc Sci, 2003;7(2):89-100. https://doi.org/10.1207/S15327841MPEE0702_3

14.Boyer C, Tremblay M, Saunders T, McFarlane A, Borghese M, Lloyd M, et al. Feasibility, validity, and reliability of the plank isometric hold as a field-based assessment of torso muscular endurance for children 8-12 years of age. Pediatr Exerc Sci, 2013;25(3):407-422. https://doi.org/10.1123/pes.25.3.407

15.Ropponen A, Gibbons LE, Videman T, Battié MC. Isometric back extension endurance testing: reasons for test termination. J Orthop Sports Phys Ther, 2005;35(7):437-442. https://doi.org/10.2519/jospt.2005.35.7.437

16. Mehdizadeh $\mathrm{R}$. The effect of core stability training on body composition and lipoprotein in menopausal older women. Iran J Ageing, 2015;10(2):159-166.

17.Kordi R, Dehghani S, Noormohammadpour P, Rostami M, Mansournia MA. Effect of abdominal resistance exercise on abdominal subcutaneous fat of obese women: A randomized controlled trial using ultrasound imaging assessments. $J$ Manipulative Physiol Ther, 2015;38(3):203-209. https://doi.org/10.1016/j.jmpt.2014.12.004

18.Cruz-Ferreira AIC, Pereira CLN, Fernandes
JA. Effects of three months of pilates-based exercise in women on body composition. Med Sci Sport Exerc, 2009;41(Supplement 1):16-17. https://doi.org/10.1249/01.MSS.0000354612.94279.58

19.Aksen-Cengizhan P, Onay D, Sever O, Doğan AA. A comparison between core exercises with Theraband and Swiss Ball in terms of core stabilization and balance performance. Isokinet Exerc Sci, 2018;26(3):183-191. https://doi.org/10.3233/IES-173212

20.Segal NA, Hein J, Basford JR. The effects of pilates training on flexibility and body composition: An observational study. Arch Phys Med Rehabil, 2004;85(12):1977-1981. https://doi.org/10.1016/j.apmr.2004.01.036

21.Arslanoglu E, Arslanoglu C, Reza B, Senel O. Effects of Eight Weeks Pilates Exercises on Body Composition of Middle Aged Sedentary Women. Phys Educ Sport Mov Heal, 2011;11(1):86-89.

22.Stanton R, Reaburn PR, Humphries B. The effect of shortterm Swiss ball training on core stability and running economy. $J$ Strength Cond Res, 2004;18(3):522-528. https://doi.org/10.1519/1533-4287(2004)18<522:TEOSSB $>$ 2.0.CO;2

23.Da Cruz TMF, Crisp MDGAH, Sindorf MAG, Verlengia R, Da Mota GR, Lopes CR. Does pilates training change physical fitness in young basketball athletes? J Exerc Physiol Online, 2014;17(1):1-10.

24.Carling C, Orhant E. Variation in body composition in professional soccer players: Interseasonal and intraseasonal changes and the effects of exposure time and player position. J Strength Cond Res, 2010;24(5):1332-1339. https://doi.org/10.1519/JSC.0b013e3181cc6154

25.Milanese C, Cavedon V, Corradini G, De Vita F, Zancanaro C. Seasonal DXA-measured body composition changes in professional male soccer players. $J$ Sports Sci, 2015;33(12):1219-1228. https://doi.org/10.1080/02640414.2015.1022573

26.Okada T, Huxel KC, Nesser TW. Relationship between core stability, functional movement and performance. J Strength Cond Res, 2011;25(1):252-261. https://doi.org/10.1519/JSC.0b013e3181b22b3e

27.Steffen K, Bakka HM, Myklebust G, Bahr R. Performance aspects of an injury prevention program: A ten-week intervention in adolescent female football players. Scand J Med Sci Sport, 2008;18(5):596-604. https://doi.org/10.1111/j.1600-0838.2007.00708.x

28. Sever O, Zorba E. Comparison of static and dynamic core exercises effects on speed and agility performance in soccer players. Isokinet Exerc Sci, 2018;26(1):29-36. https://doi.org/10.3233/IES-171120

29.Parkhouse KL, Ball N. Influence of dynamic versus static core exercises on performance in field based fitness tests. J Bodyw Mov Ther, 2011;15(4):517-524. https://doi.org/10.1016/j.jbmt.2010.12.001

30.Reed CA, Ford KR, Myer GD, Hewett TE. The effects of isolated and integrated "core stability" training on athletic performance measures: A systematic review. Sport Med, 2012;42(8):697-706. https://doi.org/10.2165/11633450-000000000-00000

31.Cressey EM, West CA, Tiberio DP, Kraemer WJ, Maresh CM. The effects of ten weeks of lowerbody unstable surface training on markers of athletic performance. J Strength Cond Res, 2007;21(2):561-567. https://doi.org/10.1519/R-19845.1

32.Myer GD, Ford KR, Palumbo JP, Hewett TE. Neuromuscular training improves performance 
and lower-extremity biomechanics in female athletes. $J$ Strength Cond Res, 2005;19(1):51-60. https://doi.org/10.1519/13643.1

33.Prieske O, Muehlbauer T, Borde R, Gube M, Bruhn S, Behm DG, et al. Neuromuscular and athletic performance following core strength training in elite youth soccer: Role of instability. Scand J Med Sci Sports, 2016;26(1):48-56. https://doi.org/10.1111/sms. 12403

34.Sever O, Kir R, Yaman M. The impact of periodized core training program on accurate service velocity of male tennis players aged 11-13. J Hum Sci, 2017;14(3):3022. https://doi.org/10.14687/jhs.v14i3.4760

35.Lephart SM, Smoliga JM, Myers JB, Sell TC, Tsai Y-S. An eight-week-golf-specific exercise program improves physical characteristics, swing mechanics, and golf performance in recreational golfers.JStrength CondRes, 2007;21(3):860-869. https://doi.org/10.1519/R-20606.1

36.Lust KR, Sandrey MA, Bulger SM, Wilder N. The effects of 6-week training programs on throwing accuracy, proprioception, and core endurance in baseball. $J$ Sport Rehabil, 2009;18(3):407-426. https://doi.org/10.1123/jsr.18.3.407

37.Mills JD, Taunton JE, Mills WA. The effect of a 10week training regimen on lumbo-pelvic stability and athletic performance in female athletes: A randomizedcontrolled trial. Phys Ther Sport, 2005;6(2):60-66. https://doi.org/10.1016/j.ptsp.2005.02.006
38.Stray-Pedersen JI, Magnussen R, Kuffel E, Seiler S, Katch F. Sling Exercise Training improves balance, kicking velocity and torso stabilization strength in elite soccer players. Med Sci Sport Exerc, 2006;38(Supplement 5): 243. https://doi.org/10.1249/00005768-200605001-01945

39. Yildizer G, Kirazci S. Effects of core stability on junior male soccer players' balance: randomized control trial. Pamukkale J Sport Sci, 2017;8(1):48-62.

40.Filipa A, Byrnes R, Paterno M V., Myer GD, Hewett TE. Neuromuscular training improves performance on the Star Excursion Balance Test in young female athletes. J Orthop Sport Phys Ther, 2010;40(9):551-558. https://doi.org/10.2519/jospt.2010.3325

41.Imai A, Kaneoka K, Okubo Y, Shiraki H. Effects of two types of trunk exercises on balance and athletic performance in youth soccer players. Int $J$ Sports Phys Ther, 2014;9(1):4757.

42. OliverGD, DiBrezzoR.Functionalbalancetrainingincollegiate women athletes. J Strength Cond Res, 2009;23(7):2124-2129. https://doi.org/10.1519/JSC.0b013e3181b3dd9e

43.Phrompaet S, Paungmali A, Pirunsan U, Sitilertpisan P. Effects of pilates training on lumbo-pelvic stability and flexibility. Asian J Sports Med, 2011;2(1):16-22. https://doi.org/ 10.5812/asjsm.34822

44. Weston M, Hibbs AE, Thompson KG, Spears IR. Isolated core training improves sprint performance in national-level junior swimmers. Int J Sports Physiol Perform, 2015;10(2):204-210. https://doi.org/ 10.1123/ijspp.2013-0488

\section{Information about the authors:}

Genc H.; http://orcid.org/0000-0003-1371-7468;hgenc@bingol.edu.tr; School of Physical Education and Sports, Bingol University; Bingol, Turkey.

Cigerci A.E. (Corresponding Author); http://orcid.org/0000-0003-3143-5982; aecigerci@kastamonu.edu.tr; School of Physical Education and Sports, Kastamonu University; Kastamonu, Turkey.

Sever O.; http://orcid.org/0000-0003-2962-3968; ozan.sever@atauni.edu.tr; Faculty of Sports Science, Ataturk University; Erzurum, Turkey.

\section{Cite this article as:}

Genc $\mathrm{H}$, Cigerci AE, Sever O. Effect of 8-week core training exercises on physical and physiological parameters of female handball players. Physical education of students, 2019;23(6):297-305.

https://doi.org/10.15561/20755279.2019.0604

This is an Open Access article distributed under the terms of the Creative Commons Attribution License, which permits unrestricted use, distribution, and reproduction in any medium, provided the original work is properly cited http://creativecommons.org/licenses/by/4.0/deed.en

Received: 23.10.2019

Accepted: 17.11.2019; Published: 18.12.2019 